\title{
Klinische und experimentelle Untersuchung der durch Ginkgofrucht verursachten Dermatitis und ihrer hautreizenden Bestandteile.
}

\author{
Von \\ Junsaku Saito. \\ (筑箱 順 作) \\ (Aus der Universitätsklinik für Dermatologie und Syphilologie \\ in Sendai. Torstand: Prof. Dr. M. Ota.)
}

\section{Einleitung.}

Ginkigo biloba L. ist eine in Japan und China sehr verbreitete Pflanze aus der Familie Ginkgoaceae (eine einzige Gattung und Art enthaltend) und wurde zuerst durch die Beschreibung von $K \ddot{m} \mathbf{m p f e r}$ (Kaempfero: Amoenitatum exoticarum. Fasc. V., 1712) in Europa und Amerika bekannt, wo sie jetzt in gemässigten Zonen als Zierbaum dient. Der Name Ginkgo stammt vom japanisch-chinesischen Schriftzeichen 銀杏 (Ginkyo), und die Verwechslung von $y$ and $g$ in den Buchstaben macht uns wieder einen seltsam exotischen Eindruck. Man nennt diesen Baum hier jedoch gewöhnlich Itcho und seine Frucht Ginnan, deren Samen eine sehr beliebte Zutat zu einigen japanischen Gerichten sind. Da man aber von alters her weiss, dass die Früchte häufig starke Hautentzündung hervorrufen, sucht man bei der Ernte die Kerne zu gervinnen, ohne dabei mit der Hand das Fleisch zu berühren. Die Ärzte werden indessen nicht selten wegen dieser Hautentzündung zu Rate gezogen, besonders im Spätherbst zur Reifezeit der Früchte.

In der Stadt Sendai und Umgegend gibt es viele Ginkgobäume, und man hat hier manchmal Gelegenheit, diese Art Dermatitis zu beobachten. Da es bisher keine eingehende Untersuchung der Ginkgodermatitis, besonders des im Fleisch enthaltenen Hautgifts gibt,* nahm ich auf Anraten

* Nach meiner ersten Publikation über die Ginkgodermatitis (XL. Sitzung d. Jap. dermato-urol. Tochtergesellschaft zu Sendai, am 2. XI. 1927) wurde das Referat eines Sitzungsberichts über dascelbe Thema ron Dr. T. Ta bay ashi veröffentlicht. (Vergl. Literatur, Nr. 11!) 


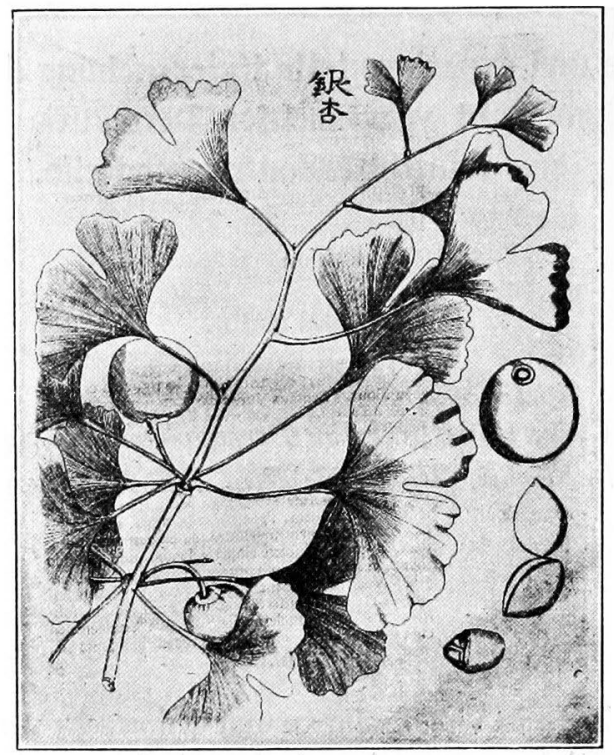

$$
\begin{aligned}
& \text { 梠银 Gimkge, vel Gin an, vulgò Itfjò. Arbor } \\
& \text { nuciferafotio Adlantino. } \\
& \text { Kk k kk } 2
\end{aligned}
$$

Fig. 1.

Ginkg̣o biloba in Kä mpfers Buch.

Prof. Otas die analytische und experimentelle Untersuchung der Giftbestandteile des Fleischs neben der klinischen und histologischen Beobachtung vor.

\section{Klinische Beobachtung der Ginkgodermatitis.}

Von unseren zahlreichen Beobachtungen wollen wir hier nur zwei Beispiele heranziehen, um den Umriss der klinischen Erscheinungen anschaulich zu machen.

Fall 1. S. I., 32jähıriger Soldat.

Anamnese: Von Geburt an gesund, hat bisher keine nennenswerten Krankheiten uberstanden, nur in seiner Jugend einmal an Rhusdermatitis gelitten. Am 4. I. 1927 beschäftigte er sich mit blossen Ḧ̈nden bei einem Bekannten mit dem Entkernen massenhaft aufbewahrter Ginkgofrüchte, und da an den Händen zähflüssiger Saft des Fruchtfleischs klebte, wusch er sie zuerst mit Wasser und dann mit etwas Weingeist. Ungeführ 30 Stunden danach empfand er an Hand- und Fingerrücken sowie auf der Beugefläche beider Vorderarme starkes Juckgefühl und kratzte sich an diesen Stellen, was Rötung zur Folge hatte. Dieser 
Juckreiz trat auch später am Gesicht auf. Alle diese Stellen waren nach 3 Tagen mit Rötung, Ödem und Papeln bedeckt, welche sich endlich auf die Genitofemoralgegend ausbreiteten und starke Juckempfindung hervorriefen. Am 4. Tag nach Beginn des Leidens holte er sich bei mir Rat.

St. pr. Grosse Statur, gute Ernährung. Allgemeinbefinden nicht gestört. Die Ilautausschlage befinden sich auf der Beuge- und Streckseite beider Vorderarme, auf dem Fingerund Handrïcken, auf der Imnenfliche beider Ober- und Unterschenkel und in Gesicht, namentlich an der Stirn, in der Umgebung der Augen und der Nase und an den Ohruusecheln. Die Handteller waren frei geblieben.

Die affizierten Stellen waren diffus gerötet, ödematös; die Grenze gegen die gesunde Partie stach ziemlich deutlich ab. Die Ausschlïge bestanden hauptsichlich aus kleinen Papeln, deren Sitz mit der Haarfollikelmündung übereinstimmte. Blischenbildung wurde nur ausnahmsweise gefunden; dagegen waren durch Kratzen erzeugte Erosionen hie und da zerstreut vorhanden. Am Gesicht, namentlich an den Augenlidern wurde starkes Ödem beobachtet, die Bindebïute waren auch hyperïmisch und trïnten. Die Vorhaut des Penis zeigte phimotische Anschwellung. Subjektiv hatte Pat. Hitzegefühl und starkes Jucken an den befallenen Stellen; auch gedrückte Stimmung und nachts Schlafitörung. Kein Fiweiss, auch keine abnormen Formbestandteile in Itarn.

Verlauf $u$. Behandlung. Durch Zinkölbepinselung und kalte Umschläge mit Natr. bicarb. -Lösung gingen Rötung, Brennen und Ödem nach 10 Tagen zurück, während das Jucken noch länger blieb. Die Ausschläge aber rezidivierten häufig durch Kratzen ; nach ungeführ zwei Wochen begann pityriatische Abschuppung, und erst nach einem vollen Ironate erfolgte rollstündige Heilung.

\section{Fall 2. I. K., 16 jühriger Kaufmannslehrling.}

Anamnese. Nach seiner Aussage im 13. Lj. an Pleuritis, in der Kindheit an Thbusdermatitis gelitten; sonst keine nennenswerte Krankheit durchgemacht. Am 23. X. 1928 sammelte er mit einem Genossen Ginkgof rüchte, wobei dieser auf den Baum kletterte, mit einer Stange Friichte abschlug und er selbst die auf den Boden gefallenen Frichte mit blossen Hünden aufammelte. Nicht nur die IÏ̈nde, sondern auch das Gesicht wurden dabei vom Saft der zerschlagenen Früchte bespritzt. Obgleich er deshalb die Hände tiichtig mit Wasser wusch, so traten doch am nächsten Morgen Rötung und Papeln auf den Iandrïcken auf, wo er wegen starken Juckens heftig kratzte. Am Morgen des 25 . X. bemerkte er auch an beiden Vorderarmen und im Gericht Rötung und Ödem, ebenfalls von starkem Jucken begleitet. Auf den Handrücken kamen auch Blïschen hinzu. Da alle diese Erscheinungen keine Neigung zur Besserung zeigten, kam Pat. zu mir, um mich zu Rat zu ziehen.

Ilautstatus. Am Gesicht, Hals und Nacken zeigten sich starke Rötung und ödernatöse Anschwellung, welche sich gegen die gesunde Partie ziemlich scharf abgrenzten. Besonders stark waren die Augenlider, Nasenfliigel und das Kinn angeschwollen. Die Conjunctiva palpebrae war hyperimisch und trïnte. Im Bereiche des Erythems gesellten sich kleine Papeln und Blïschen hinzu. Die Mundschleimhaut und der behaarte Kopfteil zeigten niehts $\Delta$ bnormes. Beide Vorderarme wiesen sowohl an der Beuge- als auch der Streckseite ausser Rötung und Ödem noch Blischen auf, welche hirsekorngross waren und häufig kleine Plaques bildeten. Nach den Platzen der Blischen entstand zuweilen eine dimne Kruste. Die Papeln, welche gewöhnlich klein waren und meistens auf den IIaarfollikelmïndungen sassen, wurden auch in der Streckseite der Vorderame beobachtet. Wihrend die Finger- und Iandrüken von all diesen Exanthemformen befallen waren, blieben die innern IIandflïchen fast unversehrt (Fig. 2). Sonst zeigten beide Ober- und Cnterschenkel sowie die 


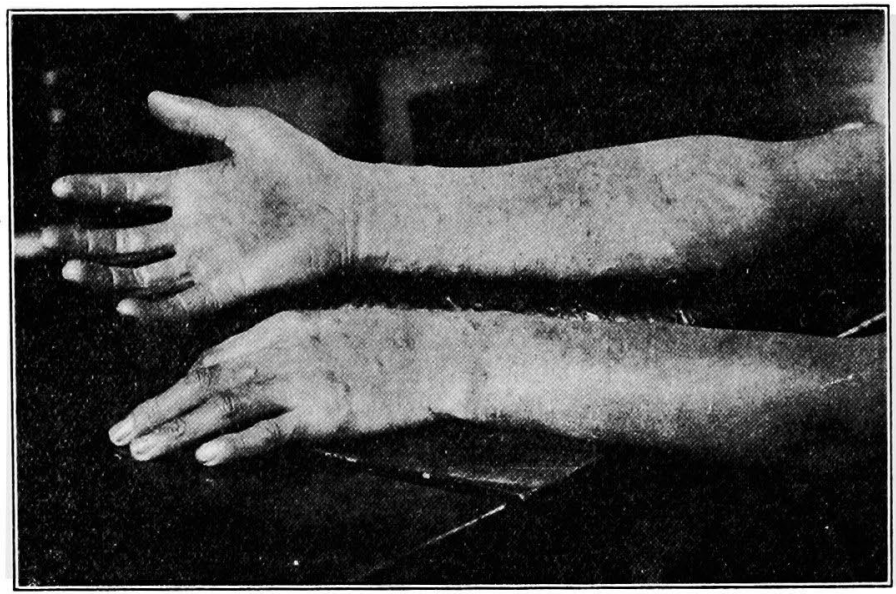

Fig. 2.

Ginkgodermatitis (Fall 2).

äusseren Genitalien ähnliche Veränderung. Die subjektiven Symptome bestanden in Jucken und Hitze- und Spannungsgefïhl an den befallenen Stellen, besonders im Gesicht, in Mattig keit und Schlafstörung. Weder Eiweiss noch Zylinder wurden im Harne nachgewiesen.

Verlauf. Vom 28. X. an nahmen Ödem und Rötung allmählich ab, und am Anfang des Novembers verschwanden alle Hautsymptome ausser Jucken, das noch ab und zu rezidivierte.

\section{Experimentell erzeugte Ginkgo-Dermatitis.}

Es unterliegt keinem Zweifel, dass es sich bei den oben besprochenen Fällen um eine durch Berührung mit der Ginkgofrucht entstandene toxische Hautentzündung handelt. Um aber diese Tatsache experimentell zu bestätigen, habe ich eine Reihe Versuche an Menschen und Tieren vorgenommen.

Als Versuchsmaterial diente einerseits ein aus zermalmtem Fleisch von alten und frischen Ginkgofrüchten ausgepresster, dicker Saft und andererseits ein alkoholischer Extrakt des Fruchtfleischs, der dadurch hergestellt wurde, dass man $200 \mathrm{~g}$ Fruchtfleisch in $400 \mathrm{cem} 80 \%$ igen Alkohols 24 Stunden lang stehen liess und den Auszug durch Filterpapier filtrierte. Diese Lösung hat eine gelblich-bräunliche Farbe und eigentümlichen Geruch. 


\section{A. Versuch bei Menschen.}

Versuchsanordnung. Ungefähr $5 \mathrm{~g}$ Fleischbrei wird direkt auf die Haut gelegt und mit dem geschlossenen Ende eines Reagenzröhrchens leicht eingerieben. Andererseits wird der alkoholische Auszug mittelst eines Wattebausches auf die Haut gestrichen und nach dem Trocknen der Stelle ein trockner Verband angelegt.

Fall 1. K. O., 30jühriger Soldat.

Angeblich hat dieser in seiner Jugend einmal Ginkgodermatitis durchgemacht. Gegen Antipyrin ist er stark empfindlich. 14. I. Die Beugefliiche des $r$. Vorderarms wurde mit Alkoholextrakt bestrichen, die des 1. Vorderarms nit Fleischfruchtsaft. Erst an Abend des nächsten Tages (ungeführ 35 Stunden nach der Manipulation) traten an beiden Stellen Jucken und Hitzegefihl auf, zu welchen sich am 16. I. Rötung gesellte. Die Reizerscheinungen verstïrkten sich allmählich; an den Haarfollikehüindungen erschienen kleine Papeln. 17. I. Rötung und ödematöse Anschwellung wurden hochgradig, sie schritten über die Grenzlinie der bestrichenen Stelle hinaus. In Vergleich zu der mit Fleischextrakt behandelten Stelle reagierte die mit alkoholischem Extrakt bestrichene Stelle weit stürker; hier sah man ausser Ödem und Papeln noch Blischenbildung. All diese Reizerscheinungen waren am 4. und 5. Tage am stürksten; darauf fingen sie allmühlich abzuklingen an. Völlige Ieilung trat erst nach 4 Wochen ein.

Fall 2. S. A., 50jührige Dienerin.

Sie hat angeblich eine starke Empfindlichkeit gegen Hautgifte.

15. I. Die Beugefliche des r. Vorderarms wurde nit Alkoholextrakt und die des 1. Vorderarms mit Fleischsaft bestrichen. 17. I, morgens (40 Stunden nach der Bestreichung) Rötung und leichtes Ödem an beiden Stellen; sonst kleine rote Papeln an Haarfollikelmündungen. Mit den Tagen vergrösserte sich die Fautentzïndung, und ihre Ausdehnung deckte sich nit dem Bereich der Bestreichung. Später schritt sie aber infolge des Kratzens uber diese Grenze hinaus und erstreckte sich nicht nur auf die ganze Beugeflüche beider Vorderarme, sondern auch auf einen Teil beider Oberarme. Brennen und Spannungsgefuihl, Schlafstörung wegen Juckens; ab und zu auch Frösteln. Auch bei diesen Falle war die entzündliche Erscheinung weit stïrker auf der Seite, die mit alkoholischem Extrakte bestrichen war. Behandlung : Zinköl und feuchte Umschläge mit Natr. bicarbon.-Lös. Nach 6 Wochen erfolgte erst Heilung nit Nachlassen der Pigmentation.

Fall 3. M. M., 28jähriger Soldat.

Fs wurde am 17. I. 1927 auf die Beugefliche beider Vorderame in ziemlich groser Ausdehnung Fruchtfleischsaft bzw. alkoholischer Extralkt gestrichen. Bei der dann 4 Tage hindurch vorgenommenen Beobuchtung bemerkte man aber keine nennenswerte Verïnderung. Er klagte nur über leichtes Jucken.

Fall 4. S. A., 18jähriger Student.

Am 17. I. 1927 wurden ihm ebenfalls beide Vorderarme mit Fleichaft und Alkoholextrakt bestrichen, was keine Reizerscheinung verursachte. 
B. Bestreichungs- und Fïterungsversuch bei Tieren.

1. Seric. Fünf Kaninchen wurden an der Innenflïche beider Ohrmuscheh mit Fleischsaft bzw. Alkoholauszug bestrichen, wobei jeuer mittelst dos stumpfen Endes eines Reagenzröhrchens 1 Minute lang leicht eingerieben, dieser mit einem Wattebausch nur leicht aufgetupft wurde. Der Versuch mit dem Fleischsaft ergab nur bei einem Fall, der mit der Alkoholextrakt bei drei Fiallen positives Resultat, das indessen nur in einem leichten Erythem mit geringer Infiltration bestand. Diese Reizerscheinung verschwand nach 4 oder 5 Tagen spurlos (Tabelle I).

Tabelle I.

\begin{tabular}{|c|c|c|c|c|c|}
\hline $\begin{array}{l}\text { Nr. d. Ver- } \\
\text { suchstiere } \\
\text { (Kaninchen) }\end{array}$ & $\begin{array}{l}\text { Körper- } \\
\text { gewicht } \\
\text { (kg) }\end{array}$ & Datum & $\begin{array}{l}\text { Frucht- } \\
\text { fleisch }\end{array}$ & $\begin{array}{l}\text { Alkobol- } \\
\text { auszug }\end{array}$ & Bemerkungen \\
\hline $\begin{array}{l}\text { I } \\
\text { II } \\
\text { III } \\
\text { VI }\end{array}$ & $\begin{array}{l}1,900 \\
2,125 \\
1,945 \\
1,875 \\
1,325\end{array}$ & $\begin{array}{l}20 . \text { I } \\
\text { do. } \\
\text { do. } \\
\text { do. } \\
\text { do. }\end{array}$ & $\begin{array}{l}- \\
- \\
- \\
+ \\
-\end{array}$ & $\begin{array}{l}\frac{t}{5} \\
\frac{1}{ \pm} \\
+ \\
+\end{array}$ & $\begin{array}{l}\text { - Keine Reaktion } \\
\text { + Positive Entzindungs- } \\
\text { reaktion wie Rötung, } \\
\text { Odem u.a. }\end{array}$ \\
\hline
\end{tabular}

2. Seric. Drei Kaninchen, welde 24 Stunden lang kein Futter erhielten, wurden mit zermalmtem Ginkgofruchtfleisch, mit Tofu-no-kara (Soyabohnenrest) gemischt, gefüttert. Wie Tabelle II zeigt, blieb eins von ihmen ohne bemerkenswerte krankhafte Erscheinung, während dic zwei anderen starke Diarrho bekamen und eins von diesen letal ondete.

Tabelle II.

\begin{tabular}{|c|c|c|c|c|}
\hline $\begin{array}{c}\text { Nr.d. Ver- } \\
\text { such-tiere } \\
\text { (Kaninchen) }\end{array}$ & $\begin{array}{l}\text { Körper- } \\
\text { gewicht } \\
(\mathrm{kg})\end{array}$ & Datum & $\begin{array}{l}\text { Futter- } \\
\text { menge } \\
(\mathrm{g})\end{array}$ & Resutalt \\
\hline $\begin{array}{l}\text { I } \\
\text { III }\end{array}$ & $\begin{array}{l}1,945 \\
1,325 \\
2,450\end{array}$ & $\begin{array}{l}23 . \mathrm{I} \\
\text { do. } \\
\text { do. }\end{array}$ & $\begin{array}{l}13,0 \\
12,0 \\
15,0\end{array}$ & $\begin{array}{l}\text { Weicher Stuhl. } \\
\text { Weicher Stuhl, ca. } 15 \text { Stunden danach Tod. } \\
\text { Keine auffallenden Veränderungen. }\end{array}$ \\
\hline
\end{tabular}

Der Sektionsbefund des gestorbenen Kaninchens war, wie folgt: Magen mit Futter gefüllt, kcin Geschwïr, keine Erosion, nur die Schleimhaut mit dickem Schleim bedeckt. Die Schleimhaut des Pylorus bis zum unteren Teil des Dünndarms war gelb gefürbt; die des Zwölffinger- und Dünndarms auffallend hyperämisch und mit gelblichem und schwach röt- 
lichem Schleim gefüllt. Im Dickdarm breiige Kotmasse enthalten; kein Fleischrest gefunden. Leber und Milz stark gestaut und dunkelrot gefürbt. Niere : keine sichtbare Veränderung. Im Harn Spur von Eiweiss nachgewiesen.

\section{Zusammenfassung und Diskussion der auf natürlichem Wege und experimentell erzeugten Ginkgodermatitis.}

Die klinische Beobachtung zeigt, dass Ginkgodermatitis immer durch direkte Berührung mit dem Fleischsaft der Frucht hervorgerufen wird. Daher kann das ätiologische Moment in jedem Falle klar verfolgt werden, was bei Rhusdermatitis nicht immer so leicht geht, da unbemerkte Berührung mit Blättern oder der Rinde der Rhuspflanze schon starke Dermatitis verursachen kann.

Die klinischen Symptome der Ginkgodermatitis sind im grossen und ganzen denen der Dermatitis venenata, namentlich der Rhusdermatitis ähnlich, so dass es schwer ist, sie einfach durch klinisches Aussehen zu unterscheiden. Die Exantheme bestehen hauptsïchlich in Erythem, Ödem und kleinen Papeln, von denen diese gewöhnlich auf den Haarfollikelmündungen sitzen und Neigung zur Gruppierung haben. Bei schweren Fällen tritt auch Bläschenbildung hinzu. Heftiges Jucken, Brennen und Spannungsgefühl sind stetige Begleiterscheinungen der Exantheme. Bindehautentzündung gesellt sich auch häufig hinzu. Schwere Störung des Allgemeinbefindens wurde niemals beobachtet.

Die Lieblingsstellen der Exantheme sind Gesicht, Hals, Nacken, Handrücken, Vorderarm, Oberschenkel und Schamgegend. Im Gesicht werden die sogen. seborrhoischen Partien besonders stark von Hautentzündung heimgesucht. Die Handteller bleiben gewöhnlich verschont. Die Inkubationszeit betrïgt bei Menschen 30-70 Stunden.

Dass das Gift, welches die Hautentzündung hervorruft, im Fleisch der Frucht cuthalten ist, wurde durch experimentelle Versuche mit Fleischsaft bzw. seinem Alkoholauszug an Menschen und Tieren sicher festgestellt. Die Symptome der experimentellen Ginkgodermatitis decken sich völlig mit denen der auf natürlichem Wege entstandenen. Es muss aber bemerkt werden, dass die Empfindlichkeit gegen dieses Gift individuell sehr verschieden ist. Gegen Rhus empfindliche Personen sind ebenfalls cmpfindlich gegen Ginkgogift.

Der Bestreichungsversuch mit Ginkgosaft oder dem Alkoholauszug ans dem Fruchtfleisch zcigt, dass das Kaninchenohr nur schwarh darauf re- 
agiert, was aber nicht in der Natur dieses Tiers beruht, da man spüter mit einem anderen Bestandteile des Fleischsafts immer starke Reaktion hervorrufen konnte. Perorale Gabe des Fleischs wirkt bei den Tieren diarrhöisch, kann sogar den Tod des Tiers herbeiführen. Es ist schon von alters her bekannt, dass Vögel niemals an der Ginkgofrucht picken.

\section{Versuch, das Gift auszuziehen.}

\section{A. Vorversuch.}

Um zu erkennen, ob der hautreizende Bestandteil des Ginkgofleischs in Wasser oder in Alkohol bzw. $\ddot{A}$ ther löslich, oder eine flüchtige Substanz ist, habe ich Auszüge aus mehreren Lösungsmitteln vorgenommen und die Giftigkeit jedes einzelnen an Menschen und Tieren ermittelt.

\section{(a) Alkoholischer Extrakt.}

$100 \mathrm{~g}$ fein zermalmten Fruchtfleischs wurden in $200 \mathrm{ccm} 80$ proz. Alkohol getaucht und nach 24 Stunden filtriert. Wenn man das gelblichbraune Filtrat auf Wasserbad abdampft, so bekommt man zwei Schichten von Flüssigkeit, eine obere geringere Menge, die dunkelrötlichbraun, ölig und alkohollöslich, und einen unteren, grösseren Teil, der gelblichbraun und wasserlöslich ist. Un zu erkennen, welche von beiden Flüssigkeiten den bautreizenden Giftstoff enthält, wurde $0,5 \mathrm{~cm}$ jeder Flüssigkeit auf die Haut solcher Personen gestrichen, deren Empfindlichkeit gegen Ginkgogift schon vorher festgestellt war. Das Ergebnis zeigt Tabelle III.

Tabelle III.

\begin{tabular}{|c|c|c|c|c|c|}
\hline Name & 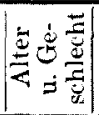 & $\begin{array}{l}\text { Empfindlich- } \\
\text { keit gegen } \\
\text { Ginkgofrucht }\end{array}$ & $\begin{array}{l}\text { Bestrichene } \\
\text { Stellen }\end{array}$ & Ölige Substanz & $\begin{array}{l}\text { Wasserlösliche } \\
\text { Substanz }\end{array}$ \\
\hline A. $\mathrm{K}$. & $\begin{array}{c}24 \\
5\end{array}$ & Mittelmässig & $\begin{array}{l}\text { Beide Vor- } \\
\text { derarme }\end{array}$ & $\begin{array}{l}\text { Ca. } 15 \text { Stunden nach Be- } \\
\text { streichen Rötung, Ôdem }\end{array}$ & Keine Reaktion \\
\hline 'T. A. & $\begin{array}{l}20 \\
\text { 早 }\end{array}$ & Schwach & do, & $\begin{array}{l}\text { und Jucken. } \\
24 \text { Stunden nach Bestrei- } \\
\text { chen leichte Rötung, } \\
\text { kleine Papeln und Juk- }\end{array}$ & do. \\
\hline M. S. & $\begin{array}{l}30 \\
9\end{array}$ & Keine & do. & $\begin{array}{l}\text { ken. } \\
\text { Nur leichtes Jucken. }\end{array}$ & do. \\
\hline
\end{tabular}

Derselbe Versuch wurde auch an zwei Kaninchen und einem Meerschweinchen angestellt, indem man beide Seiten der Rückenhaut, wo die 
Tabelle IV.

\begin{tabular}{|c|c|c|c|c|c|c|}
\hline \multirow[b]{2}{*}{ Nr. der Tiere } & \multirow{2}{*}{$\begin{array}{c}\text { Körper- } \\
\text { gewicht } \\
(\mathrm{kg})\end{array}$} & \multirow[b]{2}{*}{ Datum } & \multicolumn{2}{|c|}{ Ölige Substanz } & \multicolumn{2}{|c|}{ Wasserlösliche Substanz } \\
\hline & & & $\begin{array}{l}\text { Rechte } \\
\text { Ruicken- } \\
\text { seite }\end{array}$ & $\begin{array}{l}\text { Rechtes } \\
\text { Ohr }\end{array}$ & $\begin{array}{l}\text { Linke } \\
\text { Ruicken- } \\
\text { seite }\end{array}$ & $\begin{array}{l}\text { Linkes } \\
\text { Ohr }\end{array}$ \\
\hline $\begin{array}{l}\text { I (Kaninchen) } \\
\text { II (Kaninchen) } \\
\text { I (Meerschweinchen) }\end{array}$ & $\begin{array}{l}1,620 \\
1,860 \\
0,390\end{array}$ & $\begin{array}{l}\text { 9. II } \\
\text { do. } \\
\text { do. }\end{array}$ & $\begin{array}{l}++ \\
++ \\
++\end{array}$ & $\begin{array}{l}++ \\
++\end{array}$ & $\begin{array}{l}- \\
- \\
-\end{array}$ & - \\
\hline
\end{tabular}

Haare vorsichtig abgeschoren worden waren, mit jenem alkoholischen bzw. wässerigen Extrakt einfach bestrich. Wie man aus der Tabelle IV ersieht, war der erste stark reizend, während der letzte wirkungslos blieb. Die Stelle, wo der Alkoholauszug appliziert worden war, zeigte schon nach mehreren Stunden leichtes Erythem, nach 24 Stunden auffallende Rötung und Infiltration. Die entzündliche Reaktion trat dabei weit früher auf und war weit stärker als bei dem Betupfen mit dem ausgepressten Fleischsafte.

\section{(b) Ätherischer und petrolätherischer Extrakt.}

Fruchtfleisch wurde mit $\ddot{A}$ ther oder Petroläther ausgezogen. Aus diesem Auszug wurde $\ddot{A}$ ther bzw. Petroläther verjagt und eine dunkelrote, ölige Substanz gewonnen. $\quad 0,5 \mathrm{ccm}$ dieser Substanz wurde auf den Vorderarm eines gegen Ginkgofrucht stark empfindlichen Mannes (K. O., 30 Jahre alt) gestrichen, was bedeutende Dermatitis hervorrief. Auch bei Kaninchen und Meerschweinchen ergab sich ein positives Resultat, wie aus 'Tabelle $\mathrm{V}$ ersichtlich ist.

Tabelle V.

\begin{tabular}{|c|c|c|c|c|c|}
\hline Nr. der Tiere & $\begin{array}{l}\text { Körper- } \\
\text { gewicht } \\
(\mathrm{kg})\end{array}$ & Datum & $\begin{array}{l}\text { Bestrichene } \\
\text { Stelle }\end{array}$ & $\begin{array}{l}\text { Atherischer } \\
\text { Extrakt }\end{array}$ & $\begin{array}{l}\text { Petroläthe- } \\
\text { rischer } \\
\text { Extrakt }\end{array}$ \\
\hline $\begin{array}{l}\text { I (Kaninchen) } \\
\text { II (Kaninchen) } \\
\text { I (Meerschweinchen) }\end{array}$ & $\begin{array}{l}1,325 \\
2,140 \\
0,320\end{array}$ & $\begin{array}{l}\text { 10. II } \\
\text { do. } \\
\text { do. }\end{array}$ & $\begin{array}{l}\text { Rücken } \\
\text { do. } \\
\text { do. }\end{array}$ & $\begin{array}{l}+t \\
t+ \\
+t \\
+t\end{array}$ & $\begin{array}{l}++ \\
++ \\
++\end{array}$ \\
\hline
\end{tabular}

(c) Eingeengter Wasserextrakt.

Fein zerquetschtes Fruchtfleisch wurde zwei Tage lang in kaltem Wasser stehen gelassen. Der filtrierte Extrakt verursachte bei cinem gegen Ginkgofrucht sehr empfindlichen Manne (S. I. 32 Lij.) keine Reizer- 
scheinung. Wenn man diesen gelblichweissen, etwas getrübten Extrakt anf dem Wasserbad einengt, so bekommt man eine gelblichbraune, zähflüssige, halbtransparente und süsslich schmeckende Substanz. Diese Substanz wirkte ebenfills nicht reizend auf die Haut von Kaninchen und Meerschweinchen ('Tabelle VI).

Tabelle VI.

\begin{tabular}{c|c|c|c|c}
\hline Nir. der Tiere & $\begin{array}{c}\text { Körper- } \\
\text { gewieht } \\
(\mathrm{kg})\end{array}$ & Dutum & $\begin{array}{c}\text { Bestrichene } \\
\text { Stellen }\end{array}$ & Resultat \\
\hline I (Kaninchen) & 2,180 & $12 . \mathrm{I}$ & Ruicken und Ohr & - \\
II (Kaninchen) & 2,060 & do. & do. & - \\
I (Meerschweinchen) & 0,260 & do. & Ricken & do. \\
II (Meerschweinchen) & 0,290 & do. &
\end{tabular}

Durch die oben erwähnten Versuche konnte man feststellen, dass der hautreizende Giftstoff des Ginkgofleischs in Alkohol, Ather bzw. Petroläther löslich ist, aber nicht in Wasser, und dass die Haut von Kaninchen bzw. Meerschweinchen auch gegen diesen Giftstoff empfindlich ist.

\section{B. Auszug des Giftstoffs.}

Die im Schatten aufbewahrten, halb getrockneten Ginkgof rüchte werden nach der Entfernung der Kerne in 80 proz. Alkohol drei Tage lang stehen gelassen, dann abfiltriert und auf dem Wasserbad abgedampft. Die so entstandene dicke Masse wird wieder mit $\ddot{A}$ ther extrahiert und der $\dddot{A}$ therextrakt nach der Befreiung von $\ddot{A}$ ther in Petrolïther aufgelöst, dann mit 10 proz. Kalilauge versetzt und genügend geschüttelt. Dabei entstehen zwei Schichten Flüssigkeit, von denen man die petrolïtherlösliche Substanz von der unteren alkalischen Lösung trennt, welch letztere nach Einengung durch Vakuumdestillation mit verdünnter Salzsïure angesïuert und darauf wieder in $\ddot{A}$ ther aufgelöst wird. Dieser ätherische Extrakt wird nach mchrmaligem Waschen mit Wasser im Vakuumexsikkator stehen gelassen, wobei nadelförmige Kristalle ausscheiden. Filtriert man diese mit ihrer Mutterlauge unter starker Abkühlung ab, so bekommt man noch stark bräunlich gefürbte Kristalle, welche wiederholt in reinen Alkohol umkristallisiert werden müssen. Die so gewonnenen Kristalle sind dann weiss und haben saure Reaktion.

Der nach Kalilaugenzusatz von der alkalischen Lösung getrennte Petrolïtherauszug wird nach wiederholtem Waschen mit Wasser vom Petrol- 
äther befreit ; es ergibt sich dann eine weisse Substanz, welche in alkalischer Flüssigkeit unlöslich und von neutraler Reaktion ist.

Diese Kristalle und ihre Mutterlauge einerseits, und jene neutrale, weisse Substanz andererseits wurden zu Bestreichungsversuchen bei Menschen und Tieren verwandt. Die letzte entfaltete dabei keine hautreizende Wirkung, wenn man sie in ein wenig Weingeist auflöste und die Haut gegen die Ginkgofrucht stark empfindlicher Personen damit betrich. Dasselbe Resultat zeigte sich auch bei der Kaninchenhaut ('Tabelle VII). Die

Tabelle VII.

\begin{tabular}{|c|c|c|c|c|c|c|}
\hline Nr. der Tiere & $\begin{array}{l}\text { Körper- } \\
\text { gewicht } \\
\text { (kg) }\end{array}$ & Datum & Stellen & Kristall & $\begin{array}{l}\text { Mutter- } \\
\text { lauge }\end{array}$ & $\begin{array}{l}\text { Neutrale } \\
\text { Substanz }\end{array}$ \\
\hline I (Kaninchen) & $2, \mathrm{C} 60$ & $22.1 \mathrm{II}$ & $\begin{array}{l}\text { Riicken } \\
\text { und Ohr }\end{array}$ & + & $+t$ & - \\
\hline $\begin{array}{l}\text { II (Kaninchen) } \\
\text { I (Meerschweinchen) } \\
\text { II (Meerschweinchen) }\end{array}$ & $\begin{array}{r}1,890 \\
0,260 \\
0,290\end{array}$ & $\begin{array}{l}\text { do. } \\
\text { do. } \\
\text { do. }\end{array}$ & $\begin{array}{l}\text { do. } \\
\text { Riicken } \\
\text { do. }\end{array}$ & $\begin{array}{l}++ \\
+ \\
+\end{array}$ & $\begin{array}{l}++ \\
+t \\
+t \\
++\end{array}$ & - \\
\hline
\end{tabular}

Kristalle sowie ilıre Mutterlauge hatten dagegen stark hautreizende Wirkung. Wenn diese mit bzw. ohne Vermittlung von Alkohol auf die Haut gegen die Ginkgofrucht stark empfindlicher Personen gestrichen werden, so erscheinen schon nach 15-20 Stunden an den betreffenden Stellen Rötung und ödematöse Anschwellung. Die Reizerscheinungen waren bei der Applikation der Mutterlauge stärker als bei der der Kristalle, so dass bei jener nicht nur Erythem und Ödem, sondern auch Papeln auftraten, welche wie bei natürlich entstandenor Ginkgodernatitis auf Haarfollikelmündungen sassen. Bei gegen die Ginkgofrucht unempfindlichen Personen löste die Applikation der Kristalle sowie der Mutterlauge ebenfalls keine entzündliche Erscheinung aus ; man bemerkte nur mchrere Tage nach dem Versuche pityriatische Abschuppungen. Die Kristalle und ihre Mutterlauge konnten auch auf der Haut vou Kaninchen und Meerschweinchen entzündliche Reaktion hervorrufen, und die letzte Substanz wirkte auch hier stärker giftig (TaLelle VII). Diese stärkere Giftigkeit der Mutterlauge rührt wahrscheinlich davon her, dass diese noch genug von der im Kristall enthaltenen Substanz in sich birgt. Diesen noch nicht ganz reinen Kristall benenne ich provisorisch "Ginkgogift." 
VI. Symptome der bei Tieren durch „Ginkgogift" hervorgerufenen Dermatitis und Conjunctivitis.

Wenn man die Haut von Kaninchen, Meerschweinchen oder Affen rasiert und mit konzentrierter alkoholischer Lösung von Ginkgogiftkristallen oder ihrer Mutterlauge bestreicht, so reagiert die betreffende Hautpartie häufig schon nach 10 Stunden mit Erythem und zeigt nach ungefähr 24 Stunden ausser intensiver gewordenem Erythem noch ödematöse Schwellung (Fig. 3: ein Fall von Kaninchen). Bei stark empfindlichen Indivi-

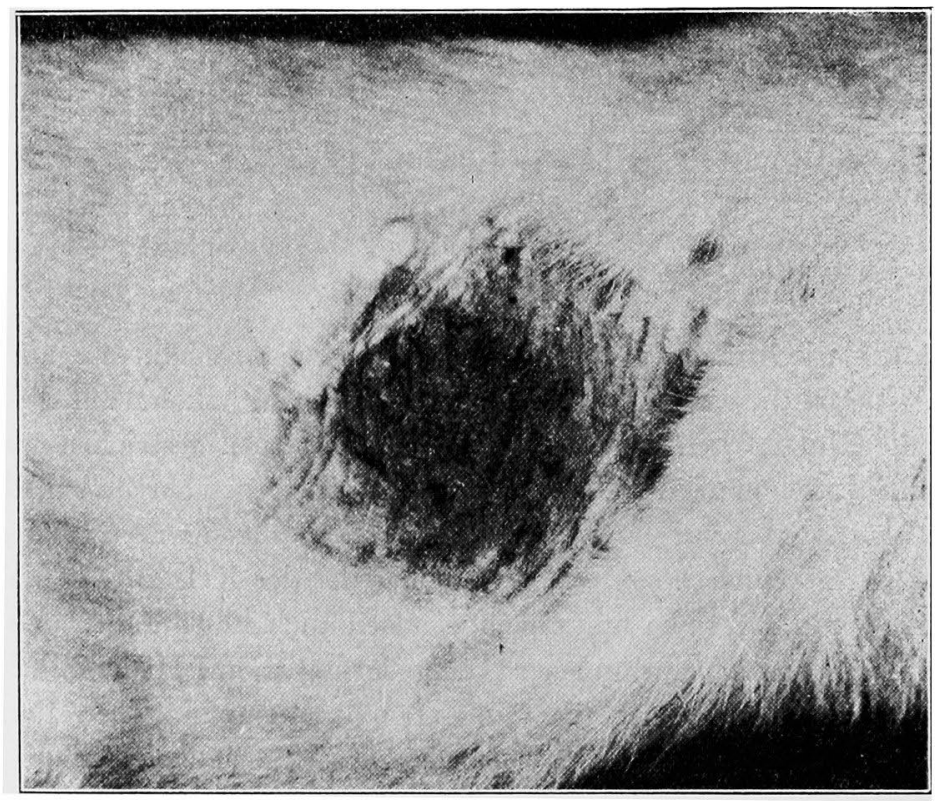

Fig. 3.

Entzïndung 24 Stunden nach Bestreichen mit Ginkgogift.

duen verdickt sich die Haut nach 48 Stunden augenfällig, wird uneben und hie und da mit rötlichbraunen Krusten bedeckt. Am Rande der befallenen Stelle beobachtet man eine wallartige, hyperämische Zone, die sich wärmer anfühlt und empfindlich zu sein scheint. Die Epidermisschicht der mit diesem Gift bestrichenen Kaninchenohren zeigt häufig schon von Anfang an nekrotische Veränderung und löst sich durch leichtes Abtupfen von der Unterlage ab. Nach 4 oder 5 Tagen fängt die Haut an runzlig zu werden, und es bilden sich dort später Rhagaden, auf deren Boden eine 
hyperämischrote Papillarschicht zu sehen ist. Nach ungeführ 10 Tagen können die Krusten leicht abgelöst werden, und es zeigt sich die durch starke Hyperämie oder Ekchymosis entstellte Oberflïche nach dem Abkratzen der Krusten. Spontan fallen sie nach ungefähr 2 Wochen ab, und uach dem Abschuppungsstadium erfolgt Heilung mit Narben. Hieraus ergibt sich, dass bei diesen Tieren durch Applikation von Ginkgogift eine weit stärkere Entzündung, mit weit kürzerer Inkubation, als bei Menschen aufzutreten pflegt. Alle diese Erscheinungen entsprechen denen bei Ätzung mit ̈̈tzmitteln überhaupt. Sie Jokalisieren sich auch bei Tieren nur an der Hautpartie, die mit dem Gift bestrichen wurde. Im Harne der erkrankten Tiere wurde niemals Eiweiss oder Zucker nachgewiesen.

Presst man eine kleine Menge Ginkgogiftkristalle in den Conjunctivalsack des Kaninchens ein, so blinzelt das Tier eine Weile, schliesst dann die Augen, und nach einer Stunde fliessen Tränen und Sekrete. Die Untersuchung am nächsten 'Tage ergibt, dass die Augenlidränder durch reichlichere Sekrete aneinander ankleben und die Lider selbst ödematisch anschwellen. Die Conjunctiva bulbi ist auch stark ödematös und hyperämisch, die obere Schicht der Cornea stark infiltriert. Die Pupillen sind verengt und die Iriszeichnung erscheint etwas undeutlich. Am dritten Tage besteht noch Hyperämie der Augen- und Lidbindehaut, in den oberen Rand der Hornhaut treten dünne Gefüisse pannusförmig cin. Die Infiltration in der Hornbaut wird unterdessen zirkumskripter und ist besonders auffallend im Papillargebiete. Die Verïnderungen der Bindehaut verschwinden erst nach 5 Tagen. Man gelangt somit zu dem Ergebnis, dass das Ginkgogift auch auf die Conjunctiva reizend wirkt.

\section{Chemische Eigenschaften des "Ginkgogifts".}

Dem vom Verfasser dargestellten Ginkgogift kommen folgende Eigenschaften zu.

1. Löst sich nicht in Wasser.

2. Löst sich in Alkalien, Alkohol, Äther, Petroläther, Chloroform, Methyl-, Amylalkohol, Benzol, Eisessig, 'Toluol, Aceton und Ölen.

3. Hat niedrigen Schmelzpunkt (ungeführ $45^{\circ} \mathrm{C}$ ).

4. Reagiert gegen Lackmuspapier sauer.

5. Ist fast geschmack- und geruchlos, wirkt aber bei lïngerem Verbleiben auf der Zunge etwas adstringierend, dann prickelnd. 
6. Verliert seine hautreizende Wirkung nicht durch Erhitzen.

7. Seine alkoholische Lösung färbt sich durch Eisenchlorid anfangs violett und dann dunkelviolett.

8. Seine alkoholische Lösung trübt sich durch Versetzen mit Blciacetat weisslich und bildet Niederschläge.

9. Beim Versetzen mit Brom verschwindet die Bromfarbe, welche bei Sättigung wieder auftritt.

\section{Literarische Übersicht über die chemische Bestandteile des Ginkgofruchtfleischs.}

Die chemische Untersuchung der Ginkgof rucht richtete sich bisher in Japan wie auch in Europa und Amerika fast ausschliesslich auf die Samenbestandteile und ergab, dass darin auch mehr oder weniger giftige Substanzen enthalten sind. Man findet somit nur wenige Mitteilungen, in denen der Ginkgobaum als Giftpflanze behandelt wird. 1857 hat Sch warzenbach zum erstenmale aus seinen Fruchtfleisch einen Kristall, ,Ginkgosiure“, isoliert und daruber in der Vierteljahrsschrift f. prakt. Pharmakologie (VI. 424) berichtet. Dies weiss ich aber nur durch die Anführung in "Die Pflanzenstoffe" von Husemann und Ifilzer; das Original konnte ich mir leider nicht beschafen. Nach der kurzen Beschreibung obiger beider Autoren muss Sch warzenbachs Ginkgosiure ungefähr so hergestellt werden: Man gewinnt durch Verdunstung des iitherischen Extrakts des Ginkgofruchtfleischs eine gelbliche, ölige, allmählich erstarrende Substanz, die sauer reagiert. Ein saurer Kristall scheidet aus der Bleiverbindung dieser Substanz nach Verjagung des Bleis durch Schwefelwasserstoff ab. Dieser hat einen Schmelzpunkt von $35^{\circ} \mathrm{C}$. Seine Formel lautet $\mathrm{C}_{2 \lambda} \mathrm{I}_{\sqrt{2}} \mathrm{CO}_{2} \mathrm{H}$. Das Kaliumblei-, Bariumblei- und Silbersalz dieses Kristalls ist eine amorphe Masse. Wehmer berichtet in seinem Buche „Die Pflanzenstoffe", dass nach älteren Angaben die Ginkgofrucht Ameisen-, Essig-, Butter-, Capron- und Valerian-, wahrscheinlich auch Propioneiure enthalten soll. Auch zitiert ex die skeptische Meinung von Trom msdorff, dass die Ginkgositure Schwarzenbachs nichts anderes als ungereinigte Essigsïure wïre. Ferner finden wir in der "Organischen Chemie" von Beilstein folgende kurze Beschreibung: Ginkgosiure $\mathrm{C}_{24} \mathrm{H}_{48} \mathrm{O}_{2}=\mathrm{C}_{23} \mathrm{H}_{47} \mathrm{CO}_{2} \mathrm{H}$. In Fruchtfieisch von Ginkgo biloba. Schmp.: $35^{\circ} \mathrm{C}$. Trotz der skeptischen Äusserung Trommsdorffs ist die Ginkgosiure Schwarzenbachs allgemein anerkannt, nur scheint $\Leftarrow$, dass über ibre Giftigkeit keine Angaben gemacht wurden.

In Japan widmet sich Dr. phil. J. Kawa mura seit einigen Jahren dem analytischen Studium der Ginkgofruchtbestandteile. Ich babe es während meiner diesbezüglichen Untersuchungen zuf̈̈llig von Dr. phil. T. K a wa i, Assistenten am chem. Institut hiesiger Universität erfahren. Dr. Kaw a mura war so liebenswürdig, mir durch Vermittlung Dr. Ka wa is seine aus Ginkgofruchtfleisch analytisch dargestellten Substanzen zur Verfügung zu stellen und weitere vergleichende, tierexperimentelle Forschnngen damit zu gestatten.

Die von $\mathrm{Kawamura}$ hergestellten Substanzen sind folgende :

1. Ginkgolsäure $\mathrm{C}_{21} \mathrm{H}_{30}(\mathrm{OH}) \mathrm{COOH}$. Schmp. : $42-43^{\circ} \mathrm{C}$, 
2. Hydroginkgolsäure $\mathrm{C}_{20} \mathrm{H}_{32}(\mathrm{OH}) \mathrm{COOH}$. Sehmp. $86-88^{\circ} \mathrm{C}$,

3. Ginkgol $\mathrm{C}_{20} \mathrm{H}_{31} \mathrm{OH}$.

4. Hydroginkgol $\mathrm{C}_{30} \mathrm{H}_{33} \mathrm{OH}$, Schmp. 50,5-51 ${ }^{\circ} \mathrm{C}$ und

5. Ginkgolmethyliather $\mathrm{C}_{20} \mathrm{H}_{31} \mathrm{OCH}_{3}$.

Die Ginkgolsäure (nicht Ginkgosïure) ist ein nadelförmiger Kristall, den $\mathrm{Ka}$ a a m u r fast durch das gleiche Verfahren wie ich gewonnen hat. Er hat ihn nämlich aus dem ätherischen Fruchtfleischextrakt, der von beigemengten freien Säuren und neutraler Substanz befreit worden war, erst als Blei- oder Silbersalz ausscheiden lassen und dann gereinigt. Wie die Molekularformel zeigt, ist diese Süure eine ungesüttigte aromatische Verbindung mit einer Hydroxyl- und einer Carboxylgruppe. Unter den Derivaten dieser Säure sind Hydrogingkolsäure und Hydroginkgol weisse Kristalle, Ginkgol und Ginkgolmethyläther ölige Substanzen. Sonst hat K aw amura eine neutrale Substanz gewonnen, welche der von mir gewonnenen, nicht hautreizenden Substanz nahe steht.

\section{Wirkung der Ginkgolsäure K a wa m uras und deren Derivate auf die Haut sowie ihre Giftigkeit und die des Ginkgogifts des Verfassers bei Mäusen.}

Wird 0,1 g Ginkgolsäure auf die mit Alkohol befeuchtete, enthaarte Haut von Kaninchen gestrichen, so tritt an der betreffenden Stelle innerhalb 20 Stunden mittelstarke, zirkumskripte Rötung und Infiltration auf; diese Hautpartie wird im Laufe der Tage dicker und bedeckt sich mit gelblichbraunen Krusten. Lokale Hitze ist auch zu fühlen. Wird eine kleine Menge dieser Säure in den Bindehautsack gebracht, so blinzelt das Tier eine Weile und schliesst dann die Augen, aus denen Tränen und Sckrete fliessen. Die Bindehaut ist hyperämisch, und die Lider schwellen ödematös an, was bis zum nüchsten Tage dauert. Die entzündlichen Reaktionen der Haut und Schlcimbaut sind also fast dieselben wie die mit meinem ,Ginkgogift" ausgelösten.

Die Giftigkeit der Ginkgoläsure und des Ginkgogifts wurde parallel an Mäusen geprüft, indem man den Tieren 2,5 prozentige Ölivenöllösung beider Substanzen intraperitoneal injizierte. Das Resultat dicser Versuche ist aus Tabelle VIII und IX zu ersehen.

Die so behandelten Tiere werden missmutig, hocken mit zusammengekrümmten Körper und mit geschlossenen Augen in einer Ecke des Küfigs nieder, ohne sich zu bewegen. Werden sie dazu gezwungen, so gehen sic die Hinterpforten nachschleppend vorwïrts. Die Atmung wird beklom- 


\section{Tabelle VIII.}

Intraperitoneale Injektion einer 2,5\% igen Lösung des Ginkgogifts in Olivenöl.

\begin{tabular}{|c|c|c|c|}
\hline $\begin{array}{l}\text { Nr. der Tiere } \\
\text { (M̈̈use) }\end{array}$ & $\begin{array}{c}\text { Körpergewicht } \\
(\mathrm{g})\end{array}$ & $\begin{array}{c}\text { Injektionsdose } \\
(\mathrm{ccm})\end{array}$ & Ausgang \\
\hline $\begin{array}{l}\text { I } \\
\text { II } \\
\text { III } \\
\text { IV } \\
\text { VI } \\
\text { VII } \\
\text { VIII } \\
\text { IX } \\
\text { X } \\
\text { XI } \\
\text { XII } \\
\text { XIII }\end{array}$ & $\begin{array}{l}15,4 \\
15,0 \\
15,0 \\
14,0 \\
14,5 \\
16,0 \\
15,0 \\
14,0 \\
14,2 \\
14,4 \\
10,5 \\
12,0 \\
13,0\end{array}$ & $\begin{array}{l}0,5 \\
0,5 \\
0,4 \\
0,4 \\
0,3 \\
0,25 \\
0,25 \\
0,2 \\
0,1 \\
0,05 \\
0,05 \\
0,05 \\
0,05\end{array}$ & $\begin{array}{l}\text { Exitus letalis nach } 1 \text { Stdn. } 40 \text { Min. } \\
\text { Exitus l. nach } 20 \text { Stdn. } \\
\text { Exitus l. nach } 2 \text { Stdn. } 30 \text { Min. } \\
\text { Exitus l. nach } 2 \text { Stdn. } 20 \text { Min. } \\
\text { Exitus I. nach } 3 \text { Stdn. } \\
\text { Nach } 2 \text { Tagen wieder munter. } \\
\text { Exitus l. nach } 4 \text { Stdn. } 30 \text { Min. } \\
\text { Exitus l. nach } 3 \text { Stdn. } \\
\text { Nach ca. } 36 \text { Stdn. wieder munter. } \\
\text { Exitus l. nach } 36 \text { Stdn. } \\
\text { Kein krank haftes Zeichen. } \\
\text { Am nächsten Tage wieder munter. } \\
\text { Kein krankhaftes Zeichen. }\end{array}$ \\
\hline
\end{tabular}

Tabelle IX.

Intraperitoneale Injektion einer 2,5\%igen Lösung der Ginkgolsäure in Olivenöl.

\begin{tabular}{c|c|c|c}
\hline $\begin{array}{c}\text { Nr. der Tiere } \\
\text { (Mïuse) }\end{array}$ & $\begin{array}{c}\text { Körpergewicht } \\
(\mathrm{g})\end{array}$ & $\begin{array}{c}\text { Injektionsdose } \\
(\mathrm{ccm})\end{array}$ & Ausgang \\
\hline I & 15,0 & 0,3 & Exitus letalis nach 4 Stdn. \\
II & 14,5 & 0,1 & Exitus l. nach ca. 8 Stdn. \\
III & 14,0 & 0,1 & An nächsten Tage wieder munter. \\
IV & 13,0 & 0,05 & Exitus l. nach 8 Stdn. \\
V & 12,0 & 0,05 & Kein krankhaftes Zeichen. \\
& Kontrolle (Olirenölinjektion) & Kein krankhaftes Zeichen. \\
I & 15,0 & 0,5 & do. \\
II & 15,0 & 0,5 & do.
\end{tabular}

men. Die letale Dosis der Ginkgosïure bei M̈̈usen von $13-14 \mathrm{~g}$ Körpergewicht entspricht ungeführ $0,05 \mathrm{ccm} 2,5$ prozentiger Ölivenöllösung, also ca. $0,1 \mathrm{~g}$ Substanz pro $\mathrm{kg}$. Die des Ginkgogifts ist beinahe gleich.

Wir haben auch mit anderen Stoffen $K$ a w a muras die hautreizende Wirkung geprüft. Hydroginkgolsäure ist ein Derivat der Ginkgolsüure, die eine Doppelverbindung von deren Seitenkette in gesiittigtem Zustand zu scin scheint. Der Bestreichungsversuch mit dieser Substanz crzielte bedeutend weniger starke entzündliche Reaktion. Wenn sie als konzentrierte Olivenöllösung oder als Kristall selbst-im letzten Falle mit ein wenig Alkohol befeuchtet-auf die enthaarte Haut von Kaninchen appliziert wird, so ruft sie nach einem Tage leichte Rötung hervor, welche am dritten Tage schon spurlos verschwindet. Die als Kontrolle gleichzeitig und auf diesclbe Weise angewandte Ginkgolsäure verursacht jene starke Reizerscheinung, die wir schon oben geschildert haben. 
Ginkgol ist eine Ginkgolsäure, welche ihre Karboxylgruppe verloren hat. Diese ist eine gelbliche ölige Substanz, welche keine Eisenchlorid-, sondern eine Niroso- und Phenolreaktion durch Diazobenzolsulfosäure gibt. Einige Tropfen dieser Substanz auf die Innenfläche der Ohrmuschel von Kaninchen gestrichen, verursachen nach ungefähr 12 Stunden leichte Rötung und Infiltration, welche nach 24 Stunden bedeutender werden (Fig. 4).

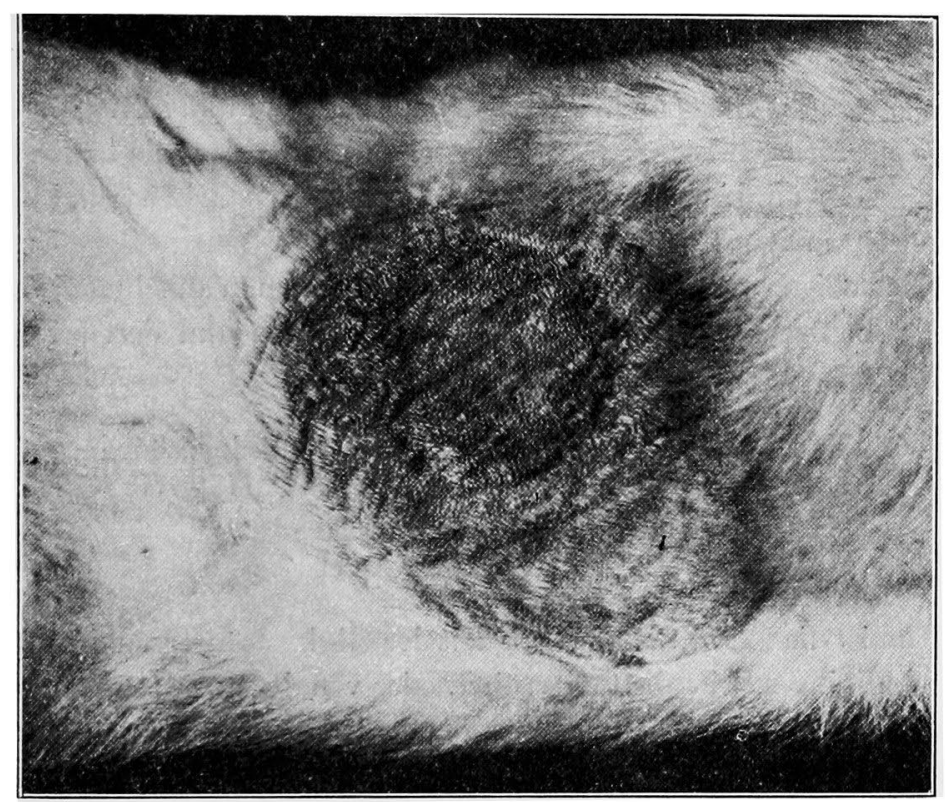

Fig. 4.

Entziindung 24 Stunden nach Bestreichen mit Ginkgol.

(Die Epidermis ist nekrotisiert.)

Nach 2 Tagen schwillt die betreffende Partie etwas an, und ihre Oberfläche erscheint grauweisslich, was beweist, dass die Epidermis hier in Nekrose geraten ist. Durch zartes Abtupfen mit Olivenölwatte kann man leicht die Oberhaut ablösen. Wird die Rückenhaut von Kaninchen ähnlich behandelt, so bilden sich hier dicke Krusten, ganz wie nach der Applikation eines starken $\ddot{A}$ tzmittels. Daraus ist zu schliessen, dass die hautreizende Wirkung bei Ginkgol stärker als bei Ginkgolsäure ist.

Ein ähnlicher Versuch wurde auch mit Hydroginkgol angestellt, das als ein Ginkgol zu betrachten ist, dessen Seitenkette sich in gesüttigtem Zustand befindet. Es ist eine gräulichweisse Substanz in Kristallform. Diese Kri- 
stalle rufen, mit etwas Alkohol befeuchtet und an die Ohrmuschel und auf die Rückenhaut von Kaninchen gestrichen, am Rande der Applikationsstelle nur leichte Rötung hervor, während die grössere zentrale Partie ohne Veränderung bleibt.

Dagegen ist die Giftigkeit des Ginkgomethy lïthers weit stärker. Dieser ist eine farblose, transparente, ölige Substanz und ist als ein Ginkgol, dessen Hydroxylgruppe verloren ist, anzusehen. Wird Ohrmuschel oder Rückenhaut mit einigen Tropfen dieser Substanz bestrichen, so treten an jener Rötung und Bläschenbildung auf; die Oberhaut des Rückens zeigt zu diesem Zeitpunkt Nässe und Neigung zum Gewebstod und ist nach 3 Tagen mit dicken Krusten bedeckt. Man ersieht hieraus, dass die hautreizende Wirkung des Ginkgolmethyläthers anch ziemlich stark ist und der der Ginkgolsäure nahe steht.

Nach obigen vergleichenden Versuchen kann man annehmen, dass betreffs der hautreizenden Wirkung der Ginkgolsäure und deren Derivate ungeführ folgendes Verhältnis besteht :

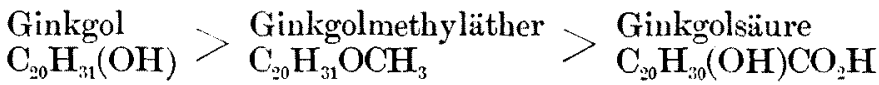

$$
\begin{aligned}
& >\underset{\mathrm{C}_{20} \mathrm{H}_{33}(\mathrm{OH})}{\mathrm{Hyd} \text { (roginkgol }}=\underset{\mathrm{C}_{20} \mathrm{H}_{32}(\mathrm{OH}) \mathrm{CO}_{2} \mathrm{H}}{\mathrm{Hyddroginkgols}}
\end{aligned}
$$

Nun ist die Frage, ob die Giftigkeit der Ginkgolsäure von der Doppelverbindung ihrer Seitenkette herrührt, oder von der $\mathrm{OH}$-Gruppe, oder ob sie eine synergetische Wirkung von diesen beiden ist. Ich möchte hier meine Vermutung darüber ïussern, dass nämlich die Doppelverbindung Pharmacophor und das Hydroxyl eine Verankerungsgruppe ist.

Es ist zwar festgestellt, dass die Ginkgodermatitis durch Ginkgogift bzw. Ginkgolsüure bedingt ist, aber es bleibt doch noch die Frage offen, ob sie die einzige hautreizende Substanz in der Ginkgofrucht ist. Wie sich aus Tabelle VII ergibt, enthält die Mutterlauge, aus welcher die Ginkgogiftkristalle ausscheiden, noch hautreizende Substanz. Um sicher zu ermitteln, ob diese Substanz ganz verschieden ist, bedarf es noch weiterer chemischer Untersuchungen.

Andererseits hat Dr. Ka w a m u ra einen neuen Bestandteil der Ginkgrofrucht, „Bilobol“, isoliert und es mir auch zur Verfügung gestellt. Es ist ein weisser, nadelförmiger Kristall mit dem Schmelzpunkt $36-37^{\circ} \mathrm{C}$, welchen er aus roher Ginkgolsäure gewonnen hat. Die Molekularformel dieses Kristalls soll nach ihm $\mathrm{C}_{21} \mathrm{H}_{34} \mathrm{O}_{2}$ sein. $\mathrm{Er}$ scheint wenigstens eine Hydroxylgruppe zu haben. 
Ich habe von diesem Bilobol je 0,02 $\mathrm{g}$ auf die Innenflüche ciner Ohrmuschel und auf die Haut einer Rückenhälfte von zwei Kaninchen und als Kontrolle je 0,05 g Ginkgolsäure auf die entsprechenden Stellen der anderen Seite desselben Tieres appliziert. Nach 24 Stunden zeigten sich an den Stellen der Kontrolltiere Rötung und Infiltration, und die Oberhaut wurde leicht ablösbar, während die mit Bilobol behandelten Stellen dunkelgrünliche, nit hyperämischem Saum umrandete Plaques darstellten, deren Oberfläche sich teilweise mit gleichfarbenen Krusten bedeckte. Diese Stellen erosierten am dritten Tage. Erst nach 4 Wochen heilte die Rückenhaut mit Hinterlassen einer seichten Narbe und Haarausfall, während an der Ohrmuschel nach einem Monate noch Erosionen zu sehen waren.

Wird die Menschenhaut mit Bilobol bestrichen, so reizt es sie auch stark. Obwohl 0,01 $\mathrm{g}$ davon auf meiner Haut keine Verïnderung verursachte, so war die Reizerscheinung durch $0,005 \mathrm{~g}$ bei einer andern Person ( $\mathrm{K}$ i m u r a, 3), die an Rhusdermatitis gelitten hatte, so stark, dass nach 24 Stunden die mit dieser Substanz bestrichene Hautpartie bedeutend vorgetrieben wurde und sich dunkelgrün verfürbte. Diese Erhabenheit war von eincm schmalen, scharfen, hyperämischen Rand umsüumt. Sie verwandelte sich nach 2 Tagen in eine grosse Blase, aus welcher bei Punktion trübe Flüssigkeit herausfloss. Die Symptome bei der Konjunktivitis durch Einführen dieser Substanz in den Bindehautsack waren beinahe ebenso wie bei Ginkgolkonjunktivitis. Man ersieht aus diesen Versuchen, dass Bilobol noch stïrkere Giftigkeit als Ginkgolsüure besitzt. Ka w a m u r a s Hydrobilobol,

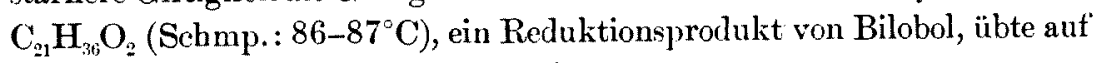
die Kaninchenohrmuschel keinen Reiz aus.

\section{Sind Ameisensäure oder andere flüchtige Gifte im Fruchtfleisch enthalten?}

Es ist auch wichtig m ermitteln, ob im Ginkgofruchtfleisch AmeisenEüure oder sonstige flüchtige Substanzen, welche hautreizend wirken, enthalten sind, da Bêch a m ps diese Säure dariu gefunden haben will.

Um zuerst allgemein die Giftigkeit der flüchtigen Bestandteile des Fruchtfleischs zn prüfen, habe ich folgende Versuche vorgenommen.

1. Alkoholischer Auszug des Fruchtfleischs, 2 Stunden lang auf Wasserbad erhitzt und verdampft, ist noch immer fähig, bei Kaninchen Dermatitis herrorzurufen, während das Destillat des dabei entstandenen Dampfes keine solche Wirkung mehr ausuabt.

2. Die leicht getrübte, weissliche, saure, durch Dampfdestillation des Fruchtfleischs gewonnene Flüssigkeit enthält keinen giftigen Stoff, der bei Menschen und Kaninchen Dermatitis verursachen kann. 
3. Das Dampfdestillat des von Alkohol befreiten alkoholisehen Auszugs des FruchtHeischs ist nicht imstande, bei Kaninchen Dermatitis hervorzurufen.

4. Alkoholischer Extrakt des Fruchtfleischs, nach Verdunsten des Alkohols ungefähr

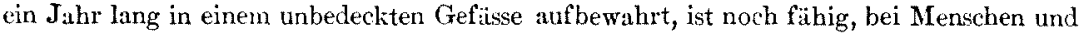
Tieren starke Hautentziindung herrorzurufen.

Nach diesen Resultaten möchten wir annehmen, dass Ginkgofruchtfleisch kein flüchtiges Hautgift enthält. Diese Annahme wird auch durch klinische Beobachtungen bestätigt, dass nämlich Ginkgodermatitis selbst bei dagegen äusserst empfindlichen Personen nur durch direkte Berührung der Ginkgofrucht hervorgerufen wird ; wir sind bis jetzt keinem dagegen sprechenden Beispiel begegnet. Wir wissen freilich auch, dass nicht blossliegende Körperteile, besonders die Genitofemoralgegend, sowie das Gesicht, wo gewöhnlich keine direkte Berührung mit der Ginkgofrucht stattfindet, häufig von der Dermatitis ergriffen werden, was aber so zu erklïren ist, dass das Gift durch die Hände oder Kleidungsstücke dorthin gebracht wurde.

Wir haben indessen mit dem Dampfdestillat des Fruchtfleischs die Ameisensäureprüfungr vorgenommen.

1. Das Destillat verindert seine Farbe durch Versetzung mit Sublimat nicht; es scheidet beim Erwärmen keinen Niederschlag aus.

2. Es trübt sich ein wenig weisslich durch Zusatz ron Silbernitrat und scheidet beim Stehenlassen eine weise Substanz aus, die sich durch Frwärmen weder löst noch vermehrt.

3. Es zeigt beim Versetzen mit einer Eisenchloridlösung gelblichrote Fürbung, die durch Erwärmen ins Dunkelrot und durch Zusatz von $\mathrm{HCl}$ ins Orangegelb übergeht.

4. Durch Hinzufitigen von Hydrargyrum oxydatum flavum fürbt es sich sch wach dunkelrot und scheidet danach eine leicht graue Substanz aus.

Auf Grund dieser Versuche ist nicht zu bestreiten, duss eine kleine Menge Ameisensäure im Ginkgofruchtfleisch enthalten ist, doch kommt sie in so geringer Menge vor, dass dadurch keine Dermatitis a usgelöst werden kann.

Es ist ohne Zweifel, dass das Fruchtfleisch ausser der Ameisensäure gewisse Mengen freier Sïuren in sich enthïlt, und es braucht vielleicht noch weiterer Untersuchungen, um zu ermitteln, ob sie sich auch an der Schaffung der Dermatitis beteiligen. Jedenfalls aber lïst sich soviel sagen, dass sie keine bedeutende Rolle dabei spielen können.

\section{Histologische Untersuchung der Ginkgodermatitis bei Menschen und Tieren.}

Der histologischen Untersuchung warde menschliche und tierische Haut unterzogen, mohdem mit dem ausgeätherten Rückstand des atheri- 
schen Extrakts von Ginkgofruchtfleisch Dermatitis auf ihr hervorgebracht worden war. Nur bei Kaninchen konnte ich die Veränderungen in verschiedenen Zeitpunkten verfolgen.

\section{A. Dermatitis bei Menschen.}

Das zur Untersuchung benutzte Material ist ein Hautstückchen aus der Beugefläche des Vorderarms, an der durch Bestreichen mit dem Giftstoffe nach 2 Tagen eine mittelmässige Dermatitis erzengt worden war. Der klinische Befund bestand ausser Jucken nur in leichtem Erythem, in welchem sich erst nach dem Betupfen mit Alkoholwatte kleine rote Papeln erkennen liessen. Dem klinischen Aussehen entsprechend, ist bei cliesem Falle die histologische Veründerung auch nur gering; sie bestand hauptsächlich in Ödem und kleinzelliger Infiltration in der Subpapillarschicht. Diese Infiltration, welche aus kleinen Rund- und Bindegewebszellen mit länglich-ovalen Kernen besteht, zeigt sich um die Gefüssnetze, besonders in der Umgebung der Haarfollikel und der-Schweissdrüsen. Einige Papillen sind stark ödematös angeschwollen und mit dilatierten Kapillaren durchsetzt, die Epidermisschicht darüber hat unregelmässig angeordnete Basalzellen, deren Protoplasma mit Vakuolen versehen und deren Kerne schlecht färbbar sind. ت̈hnliche Veränderungen sind auch in der Stachelzellenschicht zu sehen. Die Zellen sind ebenfalls schlecht fürbbar, der Kern wird häufig von der Vakuole nach der Seite gedrängt und halbmondförmig umstellt. Diese Schicht ist im allgemeinen verdickt, die Interzellularräume sind dabei erweitert. Die Körner- sowie die Hornschicht zeigt keine bedeutende Veründerungen. Man sieht ferner in einem Teile eine abnorme Vorstülpung der Epidermisschicht, die in einem Schnittprïparat, von verdickter Hornschicht umgeben, inseltörmig über der Epidermis der benachbarten Partie gelagert ist.

\section{B. Dermatitis bei Affen.}

Die Rückenhaut eines Macacus fuscatus wurde mit der oben erwähnten Giftsubstanz bestrichen. Nach 24 Stunden zeigte sich an dieser Stelle zirkumskripte Nekrose der Epidermisschicht mit scharfer, roter Demarkationslinie. Diese Schicht konnte mit Pinzette leicht von der unteren Iederhaut abgelöst werden. Zum Vergleich wurde auch ein Hautstückchen des Rückenteils, wo der Giftstoff nicht appliziert worden war, untersucht. 
Histologischer Befund der normalen Rïckenhaut. Die Oberflïche der Epidernisschicht bildet tine aufillige Wellenlinie, und die Haarfollikel sitzen in den Wellentïlern. Die Hornschicht ist ziemlich dick, die darunter liegende Epithelschicht besteht aus 3 oder 4 Lagen mit grossem Kerne versehener Zellen. Man kann weder Körner- noch Basalzellenschicht genau unterscheiden. Jur sind die Zellen in den oberen Lagen platt und die in den unteren zylindrisch. Diese Epithelzellen sind durch Stacheln miteinander vereinigt, und die Intrazellulorräume erscheinen sebr schmal. Die Haare stehen schrïg nach aussen und bald dicht, bald locker nebeneinander. An Haarfollikel findet sich Talgdrise und Arrector pili. Auch ziemlich viele Schweiscdrüsen sind vorhanden.

Ifistologischor Befund der nekrotisierten Hautpartie(24 Stunden nach Bestreichen). Die Epidermisscbicht ist zum grösseren Teile ron der Kutisschicht losgetrennt. Die Wellenlinie der Oberflïche der letzten erscheint bedeutend schlaffer als in der Norm. Die Grenze beider Schichten ist da undeutlich, wo sie noch miteinander verbunden sind, da einerseits die Anordnung der Epidermiszellen sehr unregelmüssig geworden ist und polynukleäre Leukozyten hier haufenweise eingewandert sind, und andererseits in der Kutisschicht, besonders in ihrer oberen Lage, sich ungeheure Mengen Bindegewebszellen aufgehïuft haben. Diese Zellen haben lange Kerne, drïngen sich aneinander und bilden ein dichtes Maschennetz, welches die ganze Oberfliche der nekrotisierten Kutisschicht bedeckt, in die auch Kerntrümmer und entzindliche Zellinfiltrate eingeschlossen sind. Diese bestehen hauptsïchlich aus kleinen Rundzellen und polynukleüren Leukozyten. Mastzellen sind auch vereinzelt zu sehen, aber keine Plasmazellen. Ferner befinden sich mehrere kleine Abszesse am oberen Teil der Kutisschicht. Die entzündlichen Infiltrationen sind nicht immer auf die Umgebung ron Schweiss- und Talgdrisen beschrïnkt, sondern finden sich an verschiedenen Stellen des Koriums.

\section{Dermatitis bei Kaninchen.}

\section{(a) Verïnderung 2 Stunden nach Bestreichen.}

Obwohl zu dieser Zeit makroskopisch kein Entzündungszcichen wahrzunehmen war, so erkennt man nikroskopisch sehon gewisse Verüuderungen, welche hauptsïchlich in Ödem und Zellinfiltration im oberen Teile der Kutisschicht bestehen. Die Netze der Bindegewebstusern sind in der Lederhaut des Kaninchens überhaupt locker gef ügt und werden in diesem Schnittpräparat weit lockerer; die Zellinfiltrate sind schon recht stark. Diese bestehen aus spindelförmigen Bindegewebszellen mit ovalem Kern, ausserdem noch aus eosinophilen, kleinen mononukleüren, polymorphkernigen und grösseren ovalen Zellen, welchc einen exzentrisch liegenden Kern haben. Grosse Zellen mit basophilen Granula sind auch ziemlich reichlich vorhanden. Die Epidermisschicht zeigt noch keine bemerkenswerte Veränderung (Fig. 5). 


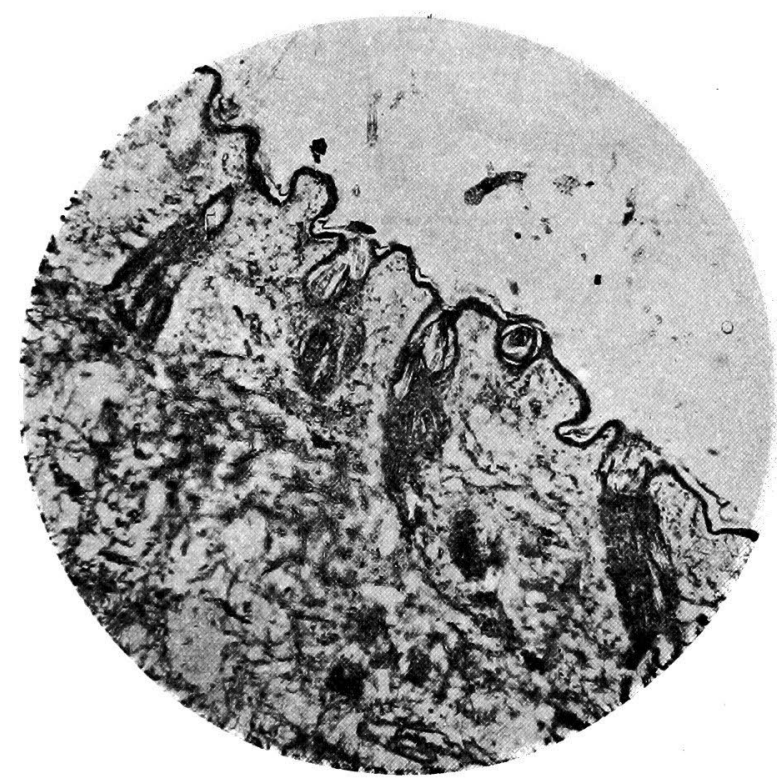

Fig. 5.

Histologische Veründerung der Kaninchenhaut 2 Stunden nach Bestreichen mit Giftbestandteil des Ginkgofruchtfleischs.

(b) Veränderung 5 Stunden nach Bestreichen.

Makroskopisch erkennt man schon zu dieser Zeit eine Rötung an der bestrichenen Hautpartie ; dementsprechend ist die histologische Veränderung schon ziemlich fortgeschritten. Wegen des Ödems im oberen Teil der Lederhaut und der Atrophie der Haarfollikel wird die Epidermis-Kutisgrenze mehr linear. Die Epidermisschicht ist dünn und besteht aus einigen unregelmässig angeordneten Zellen, deren Kerne ungleich gross sind. Im oberen Teil der Kutisschicht werden die Bindegewebsfasern locker und schlecht färbbar und schliessen in ihre weite Maschen und Spalten seröses Exsudat und aus den schon oben geschilderten Zellen bestehendes Zellinfiltrat ein. Auffallend ist die Entartung und Atrophie der Haarbälge, ihre Defekte sind schon durch Bindegewebe ersetzt. Ein Zellbündel mit langen Kernen deutet die Spur der verschwundenen Haarbälge an. In einem Teile sieht man das Bild der Nekrose. Die Epidermis ist da in eine strukturlose, homogene Masse umgewandelt und enthält hie und da Haufen von Kernen, welche sich schlecht fürben lassen. Diese Schicht geht ohne scharfe 
Grenze in die Kutisschicht über. Die Gefüssnetze der Lederhaut sind bedeutend dilatiert und mit Blut gefüllt. In keinem Schnittpräparate ist eine Talgdrüse aufzufinden (Fig. 6).

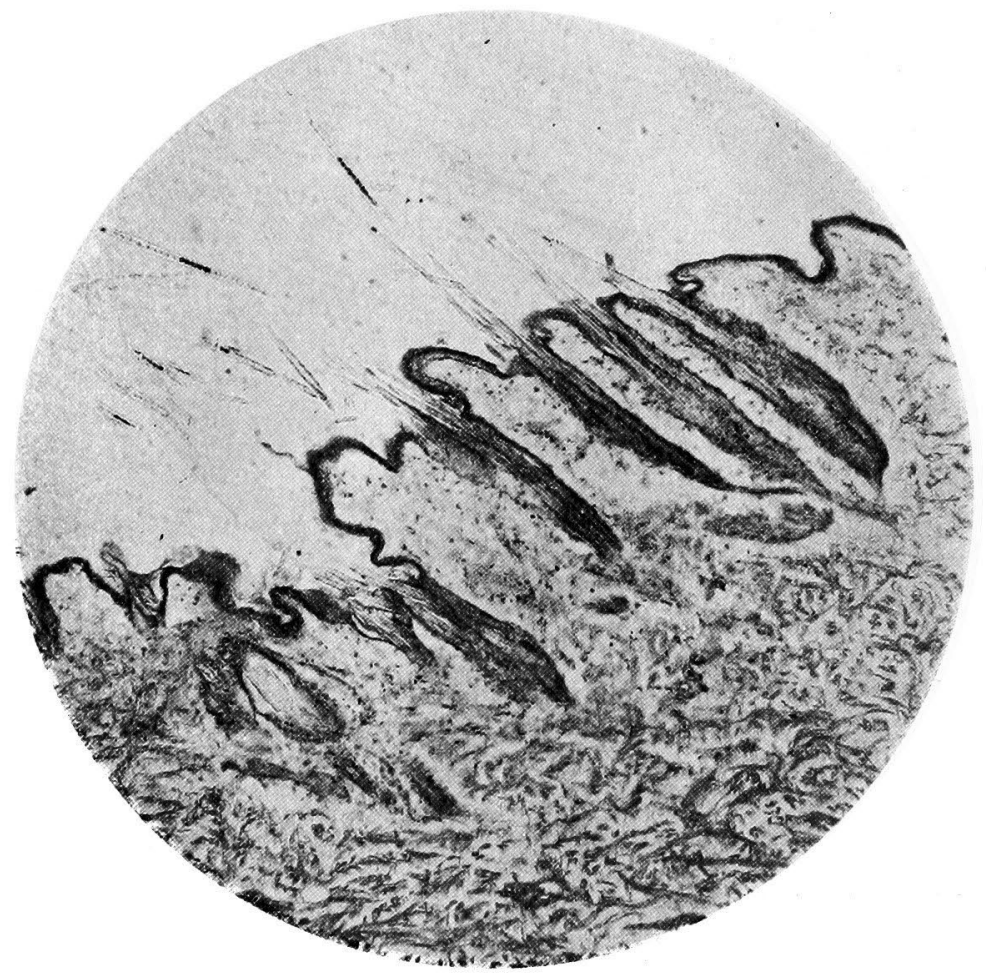

Fig. 6 .

Histologische Veränderung Kaninchenhaut 5 Stunden nach Bestreichen mit Giftbestandteil des Ginkgofruchtfleischs.

(c) Veränderung 24 Stunden nach Bestreichen.

Die bestrichene Stelle zeigte in diesem Stadium auffallendes Erythem und starke Infiltration. Die histologischen Präparate lassen jene nekrotische Veränderung, welche im vorigen Stadium nur teilweise erschien, in ganzer Ausdehnung erkennen. Die Epidermis hat ihre Kerne verloren und ist mit dem oberen Teile der Lederhaut in eine durch Erosion sich tief rot färbende Zone umgewandelt, von welcher sich die vorige nur durch den noch zurückbleibenden Farbton des Hämatoxylins unterscheiden lässt. 
Dann kommt eine schmale, sich mit Ḧ̈matoxylin schwach und schmutzig färbende, mittlere Zone, wo die Infiltrationszellen in Nekrose geraten sind und kaum ihre Kontur erkennen lassen. Zwischen diesen nekrotischen Gebieten und der unteren hypertrophierten Bindegewebsschicht liegt noch eine schmale Zone, welche hauptsächlich aus Zellinfiltrat besteht, dessen Formbestandteile aber noch gut erkennbar sind. Diese bildet nämlich eine Demarkationszone. Die Haarbälge sind stark zerstört und die subpapillaren Gefüsse hochgradig dilatiert und gestaut (Fig. 7).

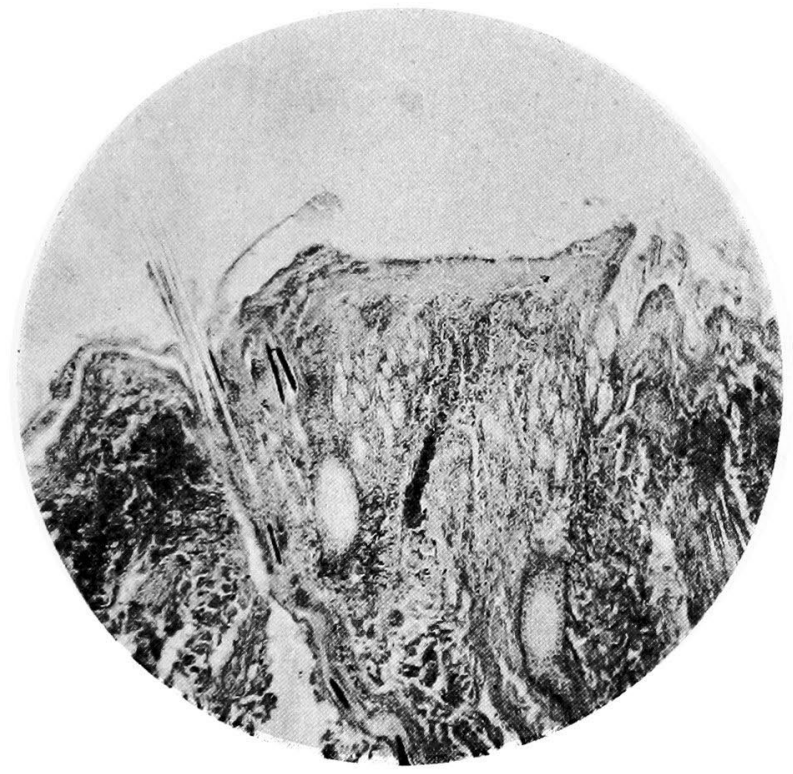

Fig. 7.

Histologische Veränderung der Kaninchenhaut 24 Stunden nach Bestreichen mit Giftbestandteil des Ginkgofruchtfleischs.

(d) Veränderung 48 Stunden nach Bestreichen.

Makroskopisch sah man zu dieser Zeit Krustenbildung. Der histologische Befund zeigt nichts anderes als weiteren Fortschritt aller jener Veränderungen, die im vorigen Zeitpunkt festgestellt wurden. Die obere breite nekrotische Zone färbt sich jetzt nicht rot, sondern blassbläulich, die mittlere schmale Zone von Zellinfiltrat ist auch schon in die Nekrose miteinbezogen ; die Kerne sind stark zerstört. Diese Zonen sind von der unteren Bindegewebsschicht abgelöst und klinisch als Kruste erkannt (Fig. 8). 


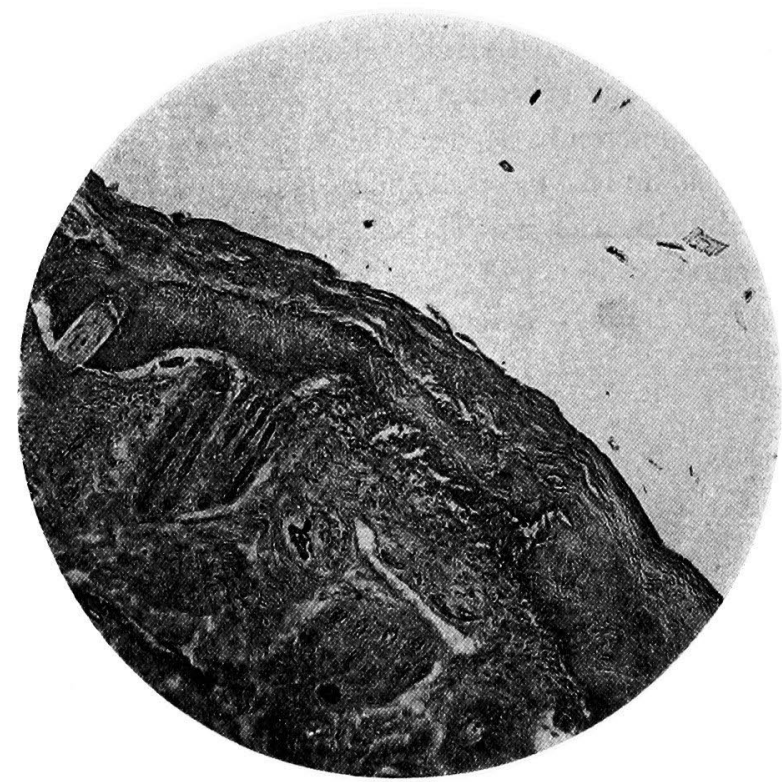

Fig. 8.

Histologische Verïnderung der Kaninchenhaut 48 Stunden nach Bestreichen mit Giftbestandteil des Ginkgofruchtfleischs.

Aus allen diesen Befunden kamn man schliessen, dass dem Gift des Ginkgofruchtfleischs wenigstens bei Kaninchen vor allem eine besonders die Epidermis und die Haarbälge schïdigende Wirkung zuzuschreiben ist.

\section{Zusammenfassung.}

(1) Die sog. Ginnan-Kabure (Ginkgo-Dermatitis) tritt ausschliesslich durch direkte Berührung mit Ginkgofruchtfleisch auf. Der ausgepresste Saft sowie der alkoholische oder ïtherische Extrakt des Fleischs rufen, zu Versuchszwecken auf die Haut gestrichen, bei Kaninchen stets, aber auch bei Menschen hüufig Dermatitis hervor.

(2) Diese Hautentzündung zeigt sich bei Menschen in Erythem, Ödem, Papeln, Bläschen u. a., die immer von starkem Jucken begleitet sind. Die Entzündungserscheinungen verschwinden meistens nach 7 bis 10 Tagen und hinterlassen pityriatische Abschuppung. Konjunktivitis gesellt sich auch manchmal dazu. Am häufigsten erscheint dieser Hautausschlag im Gesicht, an den blossliegenden Teilen der Extremitäten 
sowie an Stellen, wo die Haut überhaupt zart, dünn oder mit reichlichen Talgdrüsen versehen ist (Bengeseite der Extremitäten, innere Fläche des Oberschenkels, Genitofemoralgegend u. a.). Die Inkubationszeit beträgt 36-48 Stunden.

(3) Es scheint bei einigen Menschen eine gewisse Idiosynkrasie gegen das Gift des Ginkgofruchtfleischs zu bestehen, da nicht alle Personen von dieser Dermatitis befallen werden. Bei Kaninchen und Affen dagegen ist die Hautreizung konstant und immer ziemlich stark.

(4) Verf. gelang es, aus dem Alkohol- sowie dem Ätherextrakt ein hautreizendes Gift in Kristallform auszuziehen. Dieser Kristall ist weiss, gernch- und geschmacklos (nur etwas adstringierend bei langem Iiegenlassen auf der Zunge) und von saurer Reaktion; er löst sich in Alkohol., $\ddot{A}$ ther, Petrolïther, Alkalilösung und Ölen, aber nicht in Wasser. Wem diese Substanz mit der Haut oder der Bindehaut des Menschen und der oben erwähnten Tiere in Berührung gebracht wird, so ruft sie starke Dermatitis bzw. Konjunktivitis hervor. Eine minimale Menge dieser Sub$\operatorname{stanz}(0,05$ von $25 \%$ Olivenöllösung des Kristalls), der Maus intraperitoneal injiziert, führt den Tod des Tieres herbei. Verf. nennt diesen Kristall vorlüufig ,Ginkgogift.“

(5) Zwei Kristalle: Ginkgolsäure und Bilobol, welche Dr. phil. Kaw m ura aus Ginkgofruchtfleisch gewomnen hat, sind auch Hautgifte. Ihre Giftigkeit scheint hauptsächlich auf der Doppelverbindnng ihrer Seitenketten zu beruhen.

(6) Die flüchtigen Bestandteile des Ginkgofruchtfleischs üben keine hautreizende Wirkung aus.

(7) Die histologischen Veränderungen bei relativ leichter Dermatitis des Menschen bestehen hauptsüchlich in Odem, Gefässdilatation und Zellinfiltration in der oberen Kutisschicht; die Epidermis bleibt fast intakt. Bei Kaninchen zeigen sich Odem und Zellinfiltration der Papillarschicht schon 2 Stunden nach Bestreichen mit Ginkgogift ; nach 5 Stunden manchmal partielle Nekrose der Epidermis und der Papillen, welche sich nach 24 Stunden weit verbreitet. Die Haarfollikel werden zuerst von der Entzündung befallen; man darf sie jedoch nicht als ausschliessliche Eingangspforte des Ginkgogifts betrachten, da die von Haarfollikeln freien Partien ebenso starke Entzündungszeichen aufweisen. Das Ginkgogift scheint auch eine die Epidermis direkt ätzende Wirkung zu besitzen.

Zum Schluss spreche ich besonders meinem bochverehrten Lehrer Prof. Ot a meinen herzlichen Dank für die Anregung zu dieser Untersuchung und seine giitige Leitung withrend der Arbeit aus. Auch danke ich Herrn Dr. phil. Kawamura fiir die freundliche 
Überlassung des Materials und Herrn Dr. phil. Kaw a i für seine wertvollen Ratschlïge beim chemischen Arbeiten.

\section{Literatur.}

(1) Li Shih-Chên(李時珍), Pên tsao kan mu(本草綱目), 1588(?) Bd.30, Früchte, II.Tl.

(2) Ka emp fero, E., Anoenitatum exoticarum politico-physico-medicarum. Lemgoviae, 1712, Fasc. V, 811 .

(3) Schwarzenbach, P., Zit. bei Husemannu. Hilger (5).

(4) Béchamps, Zit. bei Wehmer (6).

(5) Husemann, A. u. Hilger, A., Die Pflanzenstoffe. Berlin 1834, 324.

(6) Wehmer, C., Die Pflanzenstoffe. Jena 1911, 2.

(7) Beilstein, Handbuch der organischen Chemie. IV. Aufl. Berlin 1920, 2, 394.

(S) M cNair, J. B., Rhusdermatitis. Chicago 1923.

(9) Tō ya ma, I. u. Ka y a ba, T., Hifuka oyobi Hinyökika Zasshi (Jap. Zts. f. Derm. u. Urol.) $1915,15,16$.

(10) Usuba, T., Mitt. ï. allg. Path. u. path. Anat., 1929, 5, 193.

(11) Tabay ashi, T., Hifuka oyobi Hinyôkika $Z$ asshi, 1927, 27, 962.

(12) K a w a mu ra, J., Jap. Journ. of Chem., 1928, 3, 89. 